\title{
SEISMIC AND NON-SEISMIC ANALYSES TO PRESERVE A CULTURAL HERITAGE MASONRY BUILDING
}

\author{
CLAUDIU SORIN DRAGOMIR ${ }^{1,2} \&$ DANIELA DOBRE ${ }^{1,3}$ \\ ${ }^{1}$ National Institute for Research and Development in Construction, Romania \\ ${ }^{2}$ University of Agronomic Science and Veterinary Medicine in Bucharest, Romania \\ ${ }^{3}$ Technical University of Civil Engineering Bucharest, Romania
}

\begin{abstract}
Romanian earthquakes in 1940 and 1977 produced severe damage to a significant number of buildings whose plans were characterized predominantly by irregularities like flexible diaphragms, structural discontinuities or $\mathrm{L}$ and $\mathrm{H}$ shapes, among others. These conceptual characteristics contributed in a decisive way to the damage or collapse of buildings designed and built according to the old seismic codes. On the other hand, European and international experience of previous strong earthquakes during the last decade shows that, in many urban areas, besides many old building, there is a number of modern $\mathrm{RC}$ buildings that do not meet the requirements of additionally improved codes for seismic-resistant design. The paper studies the behaviour of a masonry building under seismic and non-seismic actions, giving a practical and applicable interpretation of the dynamic amplification concept at the upper part of masonry buildings. Dynamic amplification effects, the types of damage and the variation of the structural rigidity after the consolidation works (compared to the initial situation), were evaluated. With respect to the instrumentation of micro-vibrations, the results obtained from the processing of the recorded micro-seismic data from 2019 emphasize the changes of the natural oscillation periods characteristic of the two directions, after applying the consolidation solution. This indicates an increase in rigidity obtained by reinforcing the building and, at the same time, it can be appreciated that the structural transfer of efforts has been made from the old structure to the new structural system. The work concludes that, in order to obtain correct information regarding the behavior of a structural system (due to the lack of data needed to create a reliable model), the contribution of each presented method is consistent, using the advantages of non-destructive methods and ambient/micro-seismic vibration monitoring.
\end{abstract}

Keywords: structural irregularities, natural oscillation period.

\section{INTRODUCTION}

Romanian Vrancea earthquakes in 1940 and 1977 have produced severe damage to a significant number of buildings whose plans were characterized predominantly by irregularities like flexible diaphragms, structural discontinuities or $\mathrm{L}$ and $\mathrm{H}$ shapes. Thus, the seismic response in the presence of torsional vibrations is an unfavourable one, with significant increases of the lateral displacements, with the negative effects related to the degradation state of the structural and non-structural elements. It is the case of both the buildings designed according to the old seismic codes, but also of the buildings that are designed in the last years. On the other hand, for such structural systems, the degree of confidence in the results of the structural calculation is much lower than in the case of symmetrical structures/without irregularities. By properly disposing of the vertical structural elements, first of all the elements with high rigidity/stiffness (walls and braced frames), the eccentricities and the decoupling of the torsional vibration modes with the translation ones must be reduced.

It can be given, as an example, the agronomist students' home built between 1928 and 1931 (Fig. 1) [1], having an L-shaped plan and the height regime basement, ground floor and 4 levels, damaged first by the earthquake in 1940, then consolidated, damaged again very severely in 1977 and demolished in 1996. 


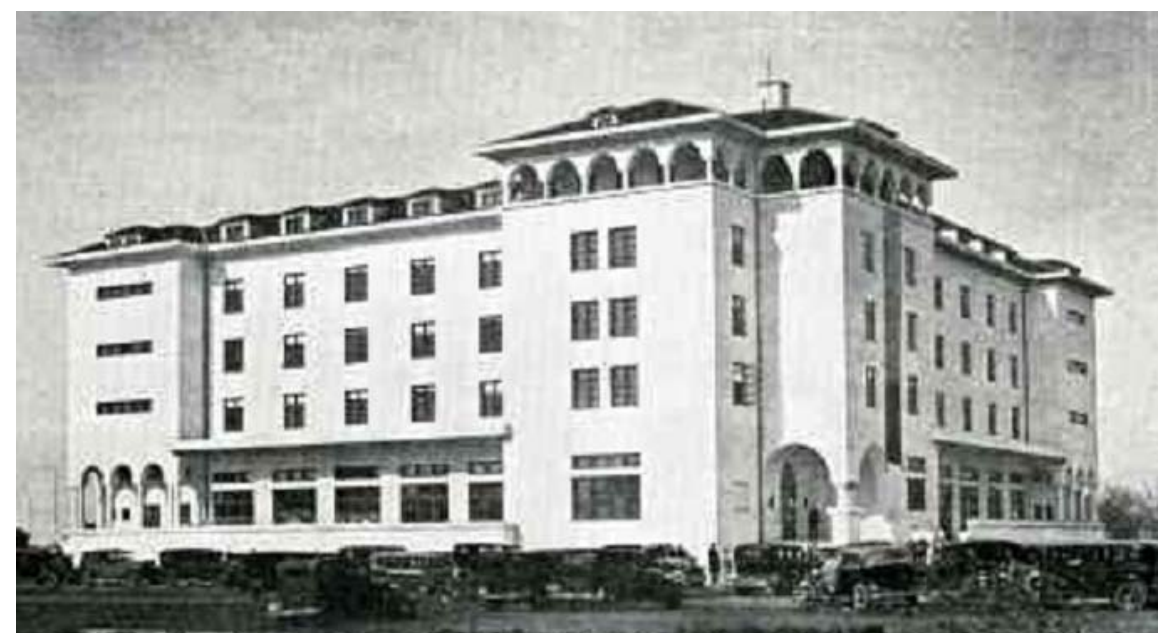

Figure 1: The agronomist students' home built in 1929 [1].

\section{SOME DATA ABOUT A STUDIED BUILDING}

The paper studies the behaviour of a masonry building under seismic and non-seismic actions giving a practical and applicable interpretation of the dynamic amplification concept at the upper part of masonry buildings.

The University of Agronomic Sciences and Veterinary Medicine of Bucharest (UASVM) has a long historical tradition, starting in 1852 during the time of Prince Barbu Stirbei, with imposing buildings, of renowned architects, some being preserved to this day. Although the studied building was designed and executed between 1950-1952, by the architect G. Negoescu (diploma in architecture in France, Versailles), it belongs to an architectural style that fits into the place, function and technical possibilities of the time (Fig. 2), [1]. The heritage value is related to the specific architecture style of this building and its cultural identity with the past history. From an architectural point of view, the building is part of an imposing, even more valuable buildings, designed by important names of Romanian architects, with international recognition, and from the historical point of view it provides some insight into what people did at the beginning of a regime, which lasted more than 40 years, as projected in relation to the trends that followed.

In plan, the building is E-shaped and is fragmented by four expansion joints into five distinct bodies $A_{1}, A_{2}, A_{3}, A_{4}$ and $A_{5}$ [2]. The height regime of the building is semi-basement, ground floor and 3 levels, in all bodies.

The structure of the building consists of load-bearing masonry walls with reinforced concrete cores and slabs made of monolithic reinforced concrete plates and beams. Along the beams or at their intersections there are supporting columns made of reinforced concrete, but not always the column continues vertically. The masonry of the supporting and partition walls is made of solid brick, double pressed, with lime-cement mortar. The reinforced concrete cores were not cast in masonry slabs, after the walls were raised, but in formworks and only afterwards were the walls erected, which thus became framed with the intention of confinement. Surprisingly, the corners of the building were neither provided with reinforced concrete columns belonging to the spatial structure nor with cores destined for brick masonry.

The brick masonry parapet that borders the roof terrace has no connection with the vertical walls of the masonry and no stiffening, in the form of risers for example, horizontally. 

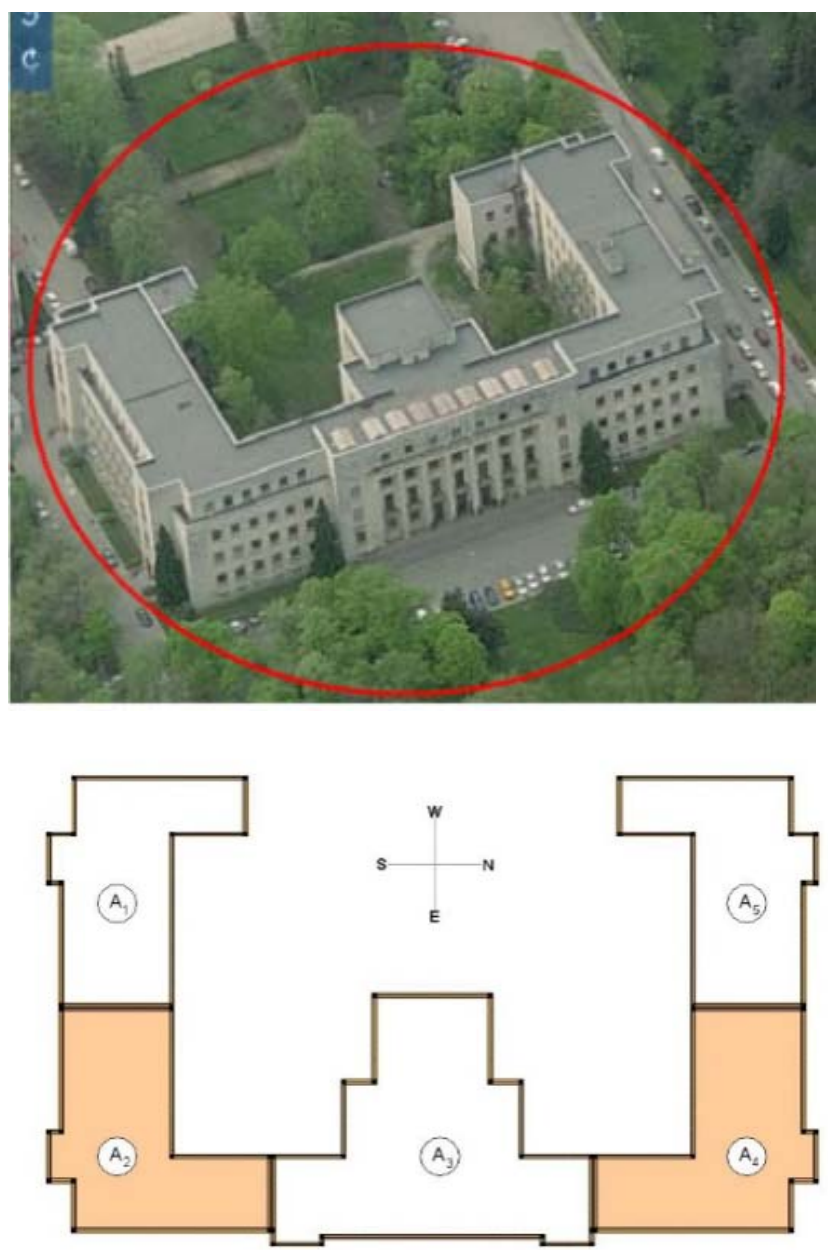

Figure 2: Plan of the shape of the U.S.A.M.V. 5 distinct bodies with irregularities [2].

Separation joints between bodies have an opening of $40 \mathrm{~mm}$, with a variation of $\pm 5 \mathrm{~mm}$, are well preserved and have the function of expansion and contraction. The free heights are $3.60 \mathrm{~m}$ on the basement and $4.50 \mathrm{~m}$ on the ground floor and floors, and in the amphitheatres and meeting rooms the heights are higher. Through these vertical dimensions, the building falls into the category of flexible buildings. Structural flexibility is also increased by the glazed surface through the size of the window openings.

The foundation system consists of rigid and insulated reinforced concrete foundations under columns. The reinforcement details are not known, but they must be specific to the 1950s. The load bearing/structural walls of brick masonry are supported by reinforced concrete foundation beams supported on column foundations.

Only the A2 body with type "L" will be analyzed in this paper. Dynamic amplification effects and the types of damage which have taken place over time, have necessitated the consolidation of this building. 


\section{ASPECTS REGARDING STRUCTURAL REGULARITY IN ELEVATION, OR PLAN, BEHAVIOR FACTOR, COMPARATIVE MODELING INTRODUCTION}

3.1 Aspects related to evaluation of structural regularity both in plane and vertically [2]

In order to determine the relative position between the two intrinsic centres, the center of gravity/the centre of mass $\left(\mathrm{X}_{\mathrm{CM}}, \mathrm{Y}_{\mathrm{CM}}\right)$ and the center of rotation/the centre of stiffness $\left(\mathrm{X}_{\mathrm{CR}}, \mathrm{Y}_{\mathrm{CR}}\right)$ (Fig. 3), some calculations were made, resulting:

$$
e_{x}=3.52 m>0.10 \times 28.00=2.80 m, \quad e_{y}=2.04 m<0.10 \times 31.50=3.15 m .
$$

Buildings with irregularity in plan floors appears to be more susceptible to large deformations and damage when they are subjected to strong ground motion than those with regular plan floors due to the additional accidental torsional forces resulting from the existing eccentricity between the center of mass and center of rigidity of the resisting elements [2]-[4].

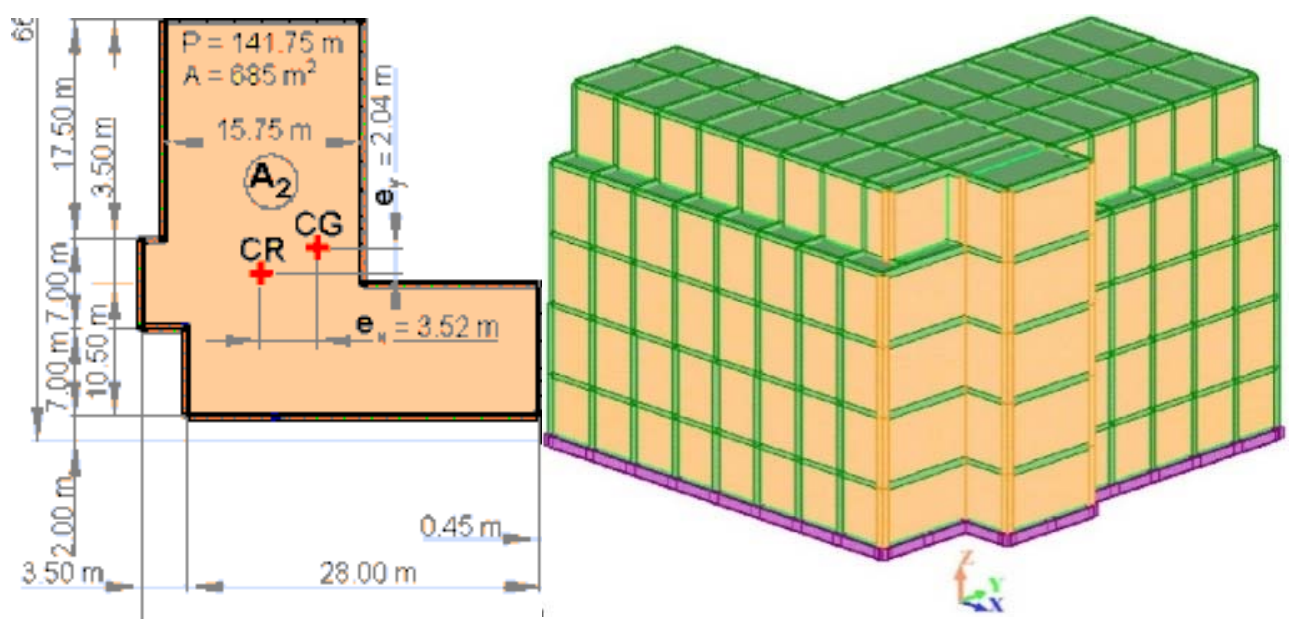

Figure 3: Spatial and plane view for $\mathrm{A}_{2}$.

\subsection{Aspects related to static and dynamic behaviour}

A structure which have asymmetric plan geometry such as L-shape, has a little energy absorbing capacity due to the torsional effects, variations of rigidity and stress concentrations at notch points of the parts. Both of the parts display different movements (Fig. 4).

For the same type of L-shaped structural system, but with larger dimensions [3], [4], displacements on the three edges in red colour, being observed different values/considerably higher (with 50\%) for the edge 1 then are than for the edge 2 and 3 are obtained (Figs 5 and 6). 


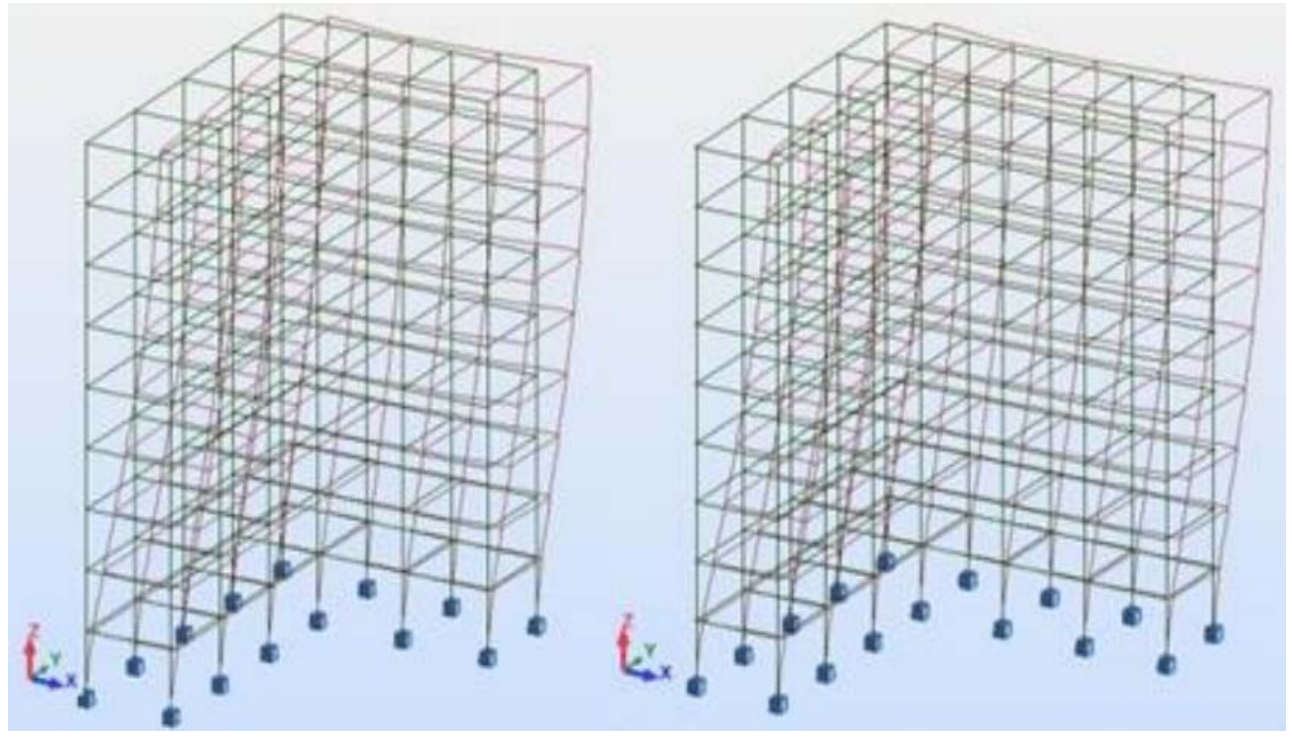

Figure 4: Displacements of two L-shaped structural systems [3], [4].

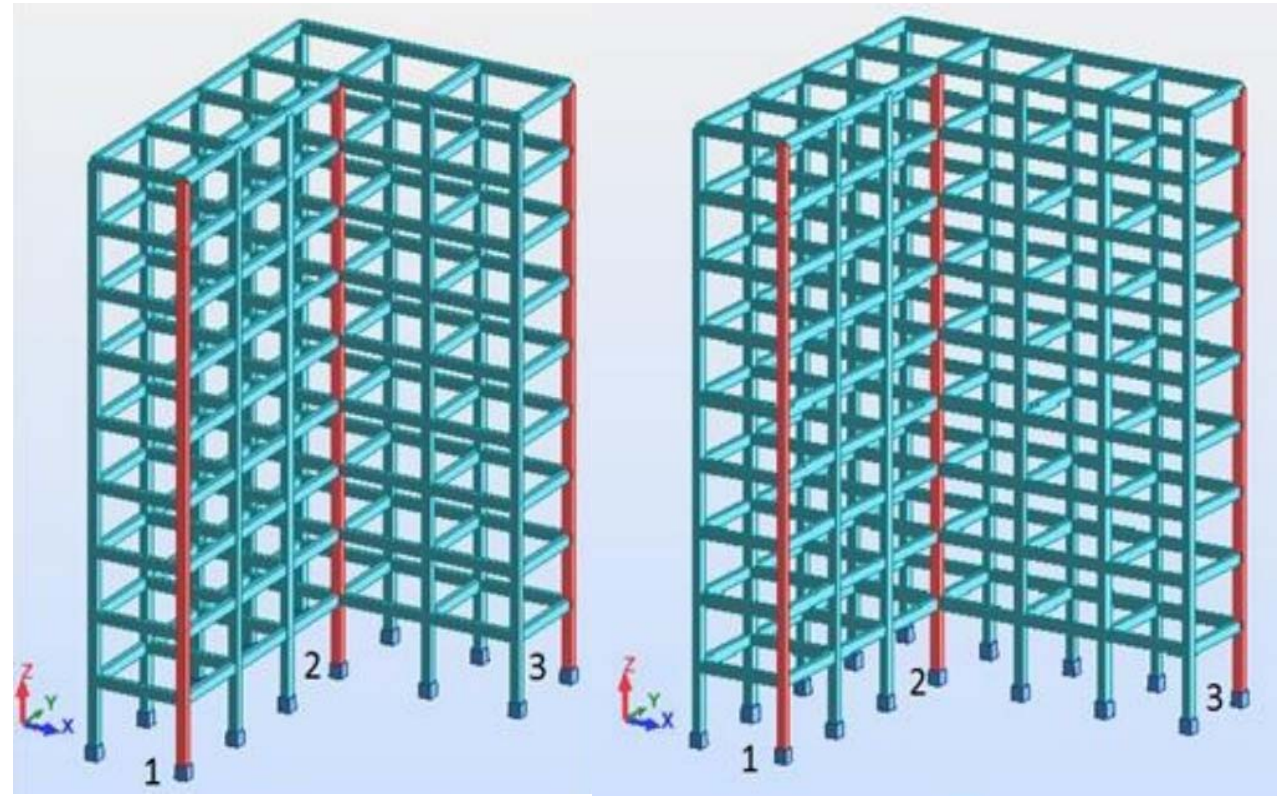

Figure 5: 3D representation of L-shaped structures with three edges emphasized [3], [4]. 


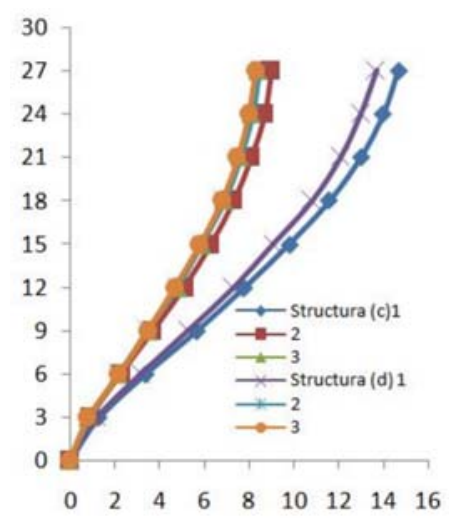

Figure 6: Comparative chart of Height (m) - displacements on x direction (mm) [3], [4].

\subsection{Aspects related to behavior factor q [5], [6]}

The behavior factor q represents the ratio between a coefficient of multiplication of the horizontal seismic force corresponding to the occurrence of the first plastic joint and a coefficient of multiplication of the horizontal seismic force corresponding to the formation of a plastic mechanism.

In the case of irregular buildings, the value of the behavior factor $\mathrm{q}$, which shall be decreased, depending on the type of this irregularity, in elevation, or plan, the type of structure. For the irregularities in elevation, the values of $q$ are reduced by $20 \%$ of the maximum values for horizontal (seismic) actions, as can be done in case of irregularities in the plan. These maximum values are established by applying formulas that take into account the ratio between the capable lateral force of the structure (achieved when a sufficient number of plastic joints have been formed to bring the structure to the threshold of the kinematic mechanism) and the lateral force corresponding to reaching the resistance capacity in the first element of the structure (the appearance of the first plastic joint).

In general, buildings with irregularities in the plane fall into the category of flexible torsion systems, for which $\mathrm{q}=3$ (high ductility class), $\mathrm{q}=2$ (medium ductility class) and $\mathrm{q}=1.5$ (low ductility class).

For this case, the behavior factor $\mathrm{q}$ has the value 4,725. The higher the behavior factor, the more structural elements must dissipate more energy through stable and predictable hysteretic behavior.

\subsection{Aspects related to the irregularity index $\alpha$ [7], [8]}

The fundamental vibration period is correlated with the height of the building, width of the building along the direction of seismic motion, the structural wall area existing at ground floor etc. The period of oscillation and the base shear force differ in the case of L-shaped buildings compared to those with regular form in plane and elevation and there are simplified formulas for these cases [7], [8].

Thus, a relationship between the irregularity index $\alpha(\alpha=0 \ldots 0.5)$ and the natural period $\mathrm{T}_{\mathrm{i}}$, respectively the base shear force $\mathrm{F}_{\mathrm{i}}$, of irregular buildings, and of those of regular buildings, $\mathrm{T}_{\mathrm{r}}$ and $\mathrm{F}_{\mathrm{r}}$ [7], [8], is shown (Fig. 7). 

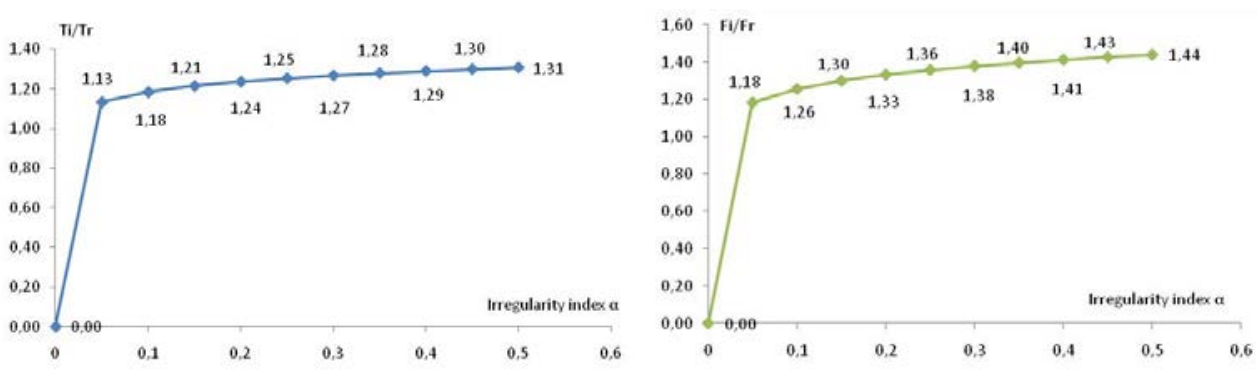

Figure 7: The relationship between the irregularity index $\alpha$ and the ratio $T_{i} / T_{r}$, respectively $\mathrm{F}_{\mathrm{i}} / \mathrm{F}_{\mathrm{r}}$.

\section{DETERMINING THE DYNAMIC STRUCTURAL CHARACTERISTICS FROM VIBRATIONS INSTRUMENTATION}

The studied building was instrumented in several stages: microseismic recordings before consolidation (2006), microseismic recordings during the period of consolidation/ strengthening work (2009) and microseismic recordings after consolidation $(2012,2019)$.

The recordings of the dynamic parameters of the building, before consolidation, were made in 2006 on the $3 \mathrm{rd}$ floor of the building. The displacements of the spatial structure in the three main directions have been successively recorded: horizontal $\mathrm{X}$, horizontal $\mathrm{Y}$ and vertical Z.

Then, some records of the dynamic parameters of the building, during the consolidation works, were made in 2009. The equipment is a seismic station equipped with 5 triaxial sensors, used for the temporary seismic instrumentation of buildings. The processing of the recorded data can be done with the GeoDAS program. For the comparative analysis of the dynamic characteristics of the building, the ARTeMIS modal calculation program was used (Fig. 8).

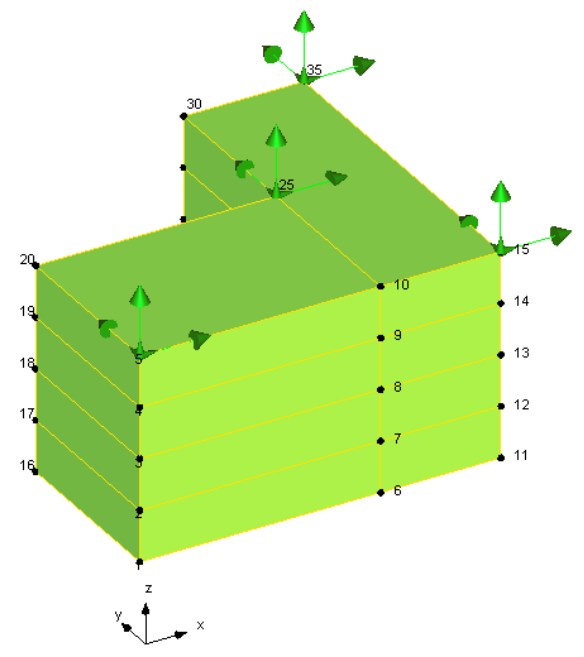

(a)

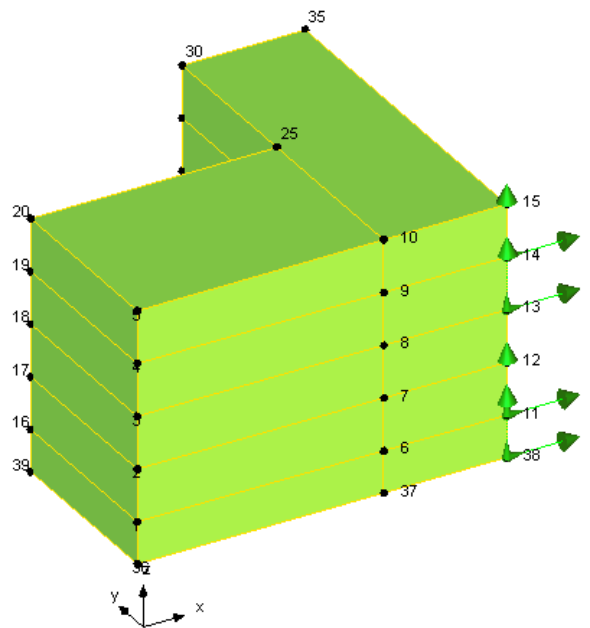

(b)

Figure 8: Sensor placement scheme in the model. (a) Horizontal; and (b) Vertical. 
The recordings were made according to two schemes for sensors: one horizontally on the 3 rd floor of the $\mathrm{A}_{2}$ body and the other vertically, with one sensor at each level. Each sensor has 3 channels corresponding to the horizontal $\mathrm{X}$, horizontal $\mathrm{Y}$ and vertical $\mathrm{Z}$ directions.

The microvibration recordings were made during the period following the structural interventions, in 2012 (Fig. 9).

The results obtained from the processing of microseismic data did not indicate significant changes in rigidity. This can be explained by the fact that at present there has been no structural transfer of efforts, from the old structure to the new reinforced concrete diaphragms. Therefore, it is necessary the seismic instrumentation of the building and the determination of a new set of values, after a future earthquake, when this structural transfer of efforts will be realized.
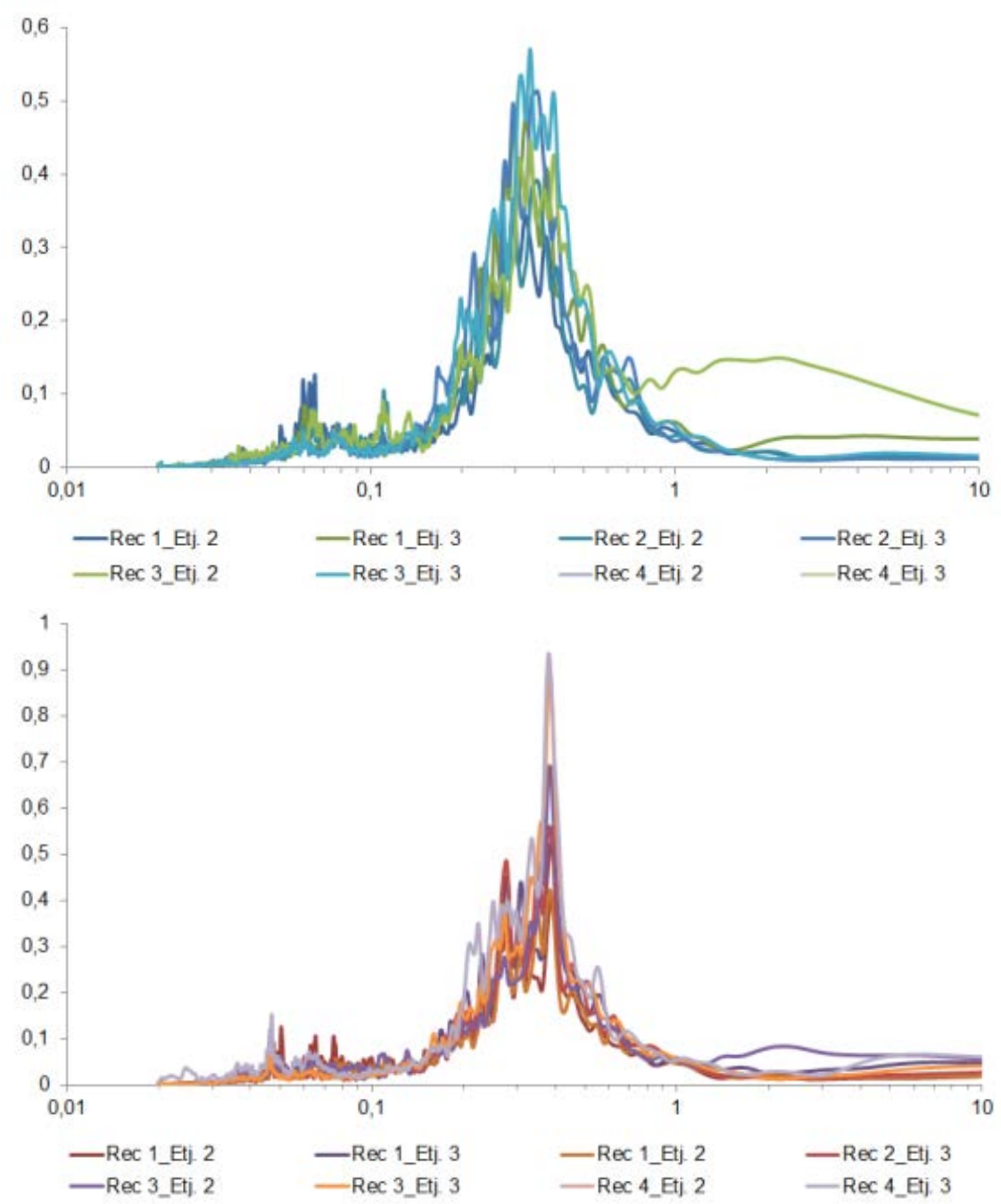

Figure 9: Fourier spectra obtained by processing the seismic response recorded for the $\mathrm{x}$ direction and the y direction. 
It should be mentioned that, during the period 2012-2019, there were recorded more seismic events with magnitude greater than 5 (www.infp.ro) and, according to those mentioned in the previous paragraph, able to lead to the transfer of efforts to the new reinforced concrete structure. The recordings were made with the help of the acquisition system consisting of 4 GMSPlus equipment, GeoSIG Switzerland. For the acquisition and processing of microseismic data, the sensors were placed on the same vertical and the GeoDAS software was used. Fast Fourier Transform FFT spectra allow us to analyze vibration amplitudes at various component frequencies on the FFT spectrum (Fig. 10).

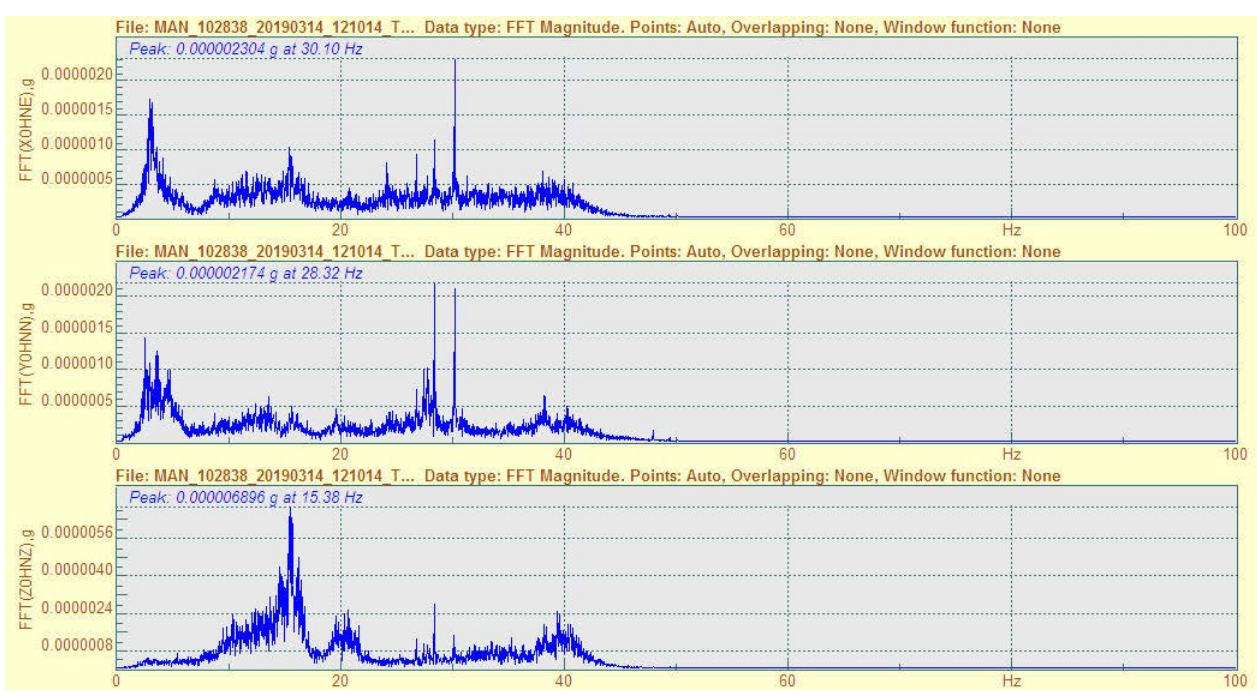

Figure 10: Fast Fourier Transform (FFT) spectrum: $f_{x}$ eval=3.0 Hz, fy $\left(\mathrm{T}_{\mathrm{x}}=0.32 \mathrm{~s}, \mathrm{~T}_{\mathrm{y}}=0.30 \mathrm{~s}\right)$.

\section{EVOLUTION OF DYNAMIC PARAMETERS DETERMINED IN DIFFERENT STEPS, IN 2016-2019 PERIOD}

The vulnerability of the whole building is of conceptual nature. Four of the 5 bodies of the building are L-shaped, i.e. they have exactly the same configuration as the students' house from (Fig. 1), which was badly damaged by the 1977 Vrancean earthquake (having a bad repair intervention after the 1940 earthquake). The L-conformation is a cause with a global effect, as a whole, and the consequence is the general torsion of each body.

The studied building $\mathrm{A}_{2}$ was modelled spatially and with a specialized program, observing differences between the natural periods of vibration thus obtained and those determined by instrumentation of microvibrations/ambient vibrations/microseisms. The calculation model idealized much the real structure, not being able to include the discontinuities, imperfections and existing damages, imperfectly rigid nodes etc.

The values obtained from the Fourier spectra for the natural oscillation periods in the described stages (the situation before consolidation, during the consolidation works, after the completion of the consolidation works) are presented in (Table 1). 
Table 1: Values of the natural periods of oscillation on the two directions of the building.

\begin{tabular}{|c|c|c|c|}
\hline The used equipment & The used software & $\begin{array}{c}\mathrm{T}_{\mathrm{x}}(\mathrm{s}) \\
(\mathrm{dir} 2)\end{array}$ & $\begin{array}{c}\mathrm{T}_{\mathrm{y}}(\mathrm{s}) \\
(\mathrm{dir} 1)\end{array}$ \\
\hline $\begin{array}{c}\text { GSR-16PC, GeoSIG Elvetia } \\
\text { before consolidation (2006) }\end{array}$ & $\begin{array}{c}\text { GeoDAS/ } \\
\text { ARTeMIS }\end{array}$ & 0.37 & 0.38 \\
\hline $\begin{array}{c}\text { GSR-16PC, GeoSIG Elvetia } \\
\text { during consolidation (2009) }\end{array}$ & $\begin{array}{c}\text { GeoDAS/ } \\
\text { ARTeMIS }\end{array}$ & 0.38 & 0.43 \\
\hline $\begin{array}{c}\text { GEODAS 12-USB, Buttan Service } \\
\text { Japonia after consolidation (2012) }\end{array}$ & $\begin{array}{c}\text { Microwave tremor } \\
\text { observation }\end{array}$ & 0.34 & 0.38 \\
\hline $\begin{array}{c}\text { GMSPlus - GeoSIG Elvetia } \\
\text { (interconnected for synchronous records) } \\
\text { after consolidation (2019) }\end{array}$ & GeoDAS & 0.32 & 0.30 \\
\hline
\end{tabular}

\section{CONCLUSIONS}

There are many types of damages caused by different plan/elevation irregularities, during Vrancea seismic events, so all the aspects listed give an image of the implications brought about by the irregularities of a structural system mainly on the oscillation period. More, evaluation and strategies for seismic energy dissipation, and also the soil class and local conditions, are to be considered [9]-[11].

Determining the dynamic structural characteristics from microvibrations/microseisms/ ambiental vibrations instrumentation, in different stages of operation of a building, apart from the static and dynamic computational performed, an evolution of structural behavior is obtained.

Consolidation consisted of cutting the entire building, in order to eliminate the general torsion phenomenon, and each body was evaluated separately, by all the approaches presented in the paper. Thus, after applying this solution, in the studied case, the natural periods, corresponding to the two horizontal directions, decreased by approx. $14 \%$ in the $x$ direction, respectively with $21 \%$ in the y direction. These values indicate an increase in rigidity, and, at the same time, it can be appreciated that the structural transfer of efforts has been made from the old structure to the new structural system obtained by the application of reinforced concrete elements.

[1] Institutul de Agricultură de la Pantelimon, (in Romanian). Online. http://usamv.ro/images/Istoric/istoric-usamv.pdf. Accessed on: 1 Sep. 2019.

[2] Dragomir, C.S., Purdoiu, S., Tronac, A.S., Cimpeanu, S.M. \& Bucur, R.D., Assessment of structural damages using non-destructive and seismic instrumentation methods. Case study of an educational building in Bucharest. Proceedings of the International Conference of the University of Agronomic Sciences and Veterinary Medicine of Bucharest "Agriculture for Life, Life for Agriculture”, 2013. 
[3] Gruia, M. \& Dragomir, C.S., Enhancing the structural behaviour of reinforced concrete buildings under seismic actions. Journal of Young Scientist, 2. Online. http://journalofyoungscientist.usamv.ro/pdf/vol_II_2014/art7.pdf. Accessed on: 1 Sep. 2019.

[4] Dragomir, C.S., Dynamic amplification of irregular buildings (in Romanian). Online. http://constructii.incd.ro/Archive/2009-1/2009-1-5.pdf. Accessed on: 1 Sep. 2019.

[5] Seismic design code, P100-1/2013. Part I - Design prescriptions for buildings (in Romanian).

[6] Fardis, M.N., Design of buildings for earthquake resistance, according to Eurocode 8Part 1 (Buildings and concrete buildings), Eurocodes. Online. https://eurocodes.jrc.ec.europa.eu/doc/WS2008/EN1998_2_Fardis.pdf. Accessed on: 1 Sep. 2019.

[7] Kewalramani, M.A. \& Syed, Z.I., Seismic Analysis of Torsional Irregularity in MultiStorey Symmetric and Asymmetric Buildings. Eurasian Journal of Analytical Chemistry, 13(3), 2018. Online. http://www.eurasianjournals.com/SeismicAnalysis-of-Torsional-Irregularity-in-nMulti-Storey-Symmetric-and-Asymmetric, 108871,0,2.html. Accessed on: 1 Sep. 2019.

[8] Korkmaz, H.H., Overhangs in structural systems and earthquake behaviour from torsional irregularity point of view. Selcuk University Journal of Engineering, Science and Technology, 2018.

[9] Luca, S.G., Pastia, C., Toma, I.O. \& Budescu, M., Control Strategies for Seismic Energy Dissipation. Proceedings of the 14th SGEM GeoConference on Science and Technologies in Geology, Exploration and Mining, 2014.

[10] Luca, S.G., Pastia, C., Budescu, M., Teodoru, I. \& Bejan, F., Evaluation of seismic energy in structures using passive fluid dampers. Proceedings of the 15th SGEM GeoConference on science and technologies in geology, exploration and mining, 2015.

[11] Dobrescu, C.F., Study concerning bearing assessment of natural and stabilized soils using binders with ecological benefits based on parametric correlations. Romanian Journal of Materials, 47(1), pp. 112-116, 2017. 